\title{
Genes that modulate the frequency of mutation at meiosis
}

\author{
Ronald H. F. Hunter ${ }^{1}$ and Niels Einer-Jensen ${ }^{2}$
}

If trained as a mammalian reproductive physiologist, one is not best placed to make an original contribution to the discipline of genetics. However, consideration of nuclear events in germ cells may serve as a bridge between the two fields of study.

Because most mutations are deleterious, one might anticipate that any tendency towards such expensive mistakes need to be eliminated. This remark prompts a key question that appears to have been overlooked in the established literature, viz., is the frequency of mutation in the germ cell line preserved at a minimum threshold so that a basis for natural selection is invariably present? If so, is there a gene or sequence of genes to facilitate a minimum rate of mutation? It seems improbable that such a key aberration would be left wholly to chance. To be effective, a corollary would require a means of inhibiting the occurrence of too high a mutation frequency in the germ cell line: in other words, some form of genetic homeostasis, such as a feedback system that monitors and optimizes the incidence of mutation at meiosis. Random and DNA-guided mutations may co-exist.

As of this writing, the identity of such putative genes is a matter of speculation. However, it could become the focus of research and offer an exciting bridge between reproductive physiology and molecular genetic.

Conflict of interest

The authors declare that they have no conflict of interest.

\section{Publisher's note \\ Springer Nature remains neutral with regard to jurisdictional claims in published maps and institutional affiliations.}

Received: 21 December 2017 Accepted: 29 January 2018. Published online: 20 April 2018 